\title{
Psychosocial Flag Signs in Patients with Compensable Occupational Lumbar Spine Injuries
}

\section{Razmjou $\mathrm{H}^{* 1,2,3}$}

${ }^{1}$ Holland Orthopaedic \& Arthritic Centre, Working Condition Program, Sunnybrook Health Sciences Centre, Toronto, Canada

${ }^{2}$ Department of Physical Therapy, Faculty of Medicine, University of Toronto, Toronto, Canada

${ }^{3}$ Sunnybrook Research Institute, Sunnybrook Health Sciences Centre, Toronto, Canada

*Corresponding author: Razmjou H, Holland Orthopaedic and Arthritic Centre, 43 Wellesley Street East, Toronto, Ontario, Canada M4Y 1H1, Tel: (416) 967-8654, E-mail: helen.razmjou@sunnybrook.ca

Citation: Razmjou H (2018) Psychosocial Flag Signs in Patients with Compensable Occupational Lumbar Spine Injuries. J Orthop Physiother 1(1): 101. doi: 10.15744/2639-930X.1.101

Received Date: December 02, 2017 Accepted Date: September 18, 2018 Published Date: September 20, 2018

\begin{abstract}
Purpose: The purposes of this study were to examine the prevalence of psychological flag signs (yellow, black and blue) in workers who had sustained a low back injury and to examine the relationship between the presence and number of these signs and the level of pain, disability, anxiety, depression and ability to work.

Methods: This study involved a review of the electronic files of injured workers with an active work-related claim related to the lumbar spine. The information on demographics, presence and number of psychosocial and workplace risk factors, level of disability as measured by the Roland Morris Disability Questionnaire (RMDQ), pain intensity as measured by the numeric pain rating scale (NPRS), and anxiety and depression as measured by the Hospital Anxiety and Depression Scale (HADS) was extracted from standardized forms.

Results: Data of 250 consecutive patients, $74(30 \%)$ females, $176(70 \%)$ males, mean age=45(11) were reviewed. Flag signs had a prevalence of $173(69 \%), 162(65 \%)$ and 46(18\%) for yellow, black and blue categories respectively. Thirty nine (16\%) patients had no flag signs (Group1). Of the remaining patients, 109 (43\%) had one or two flag signs (Group2) and 102 (41\%) had three or more flag signs (Group3). There was a statistically significant relationship between presence and number of flag signs and chronicity $(\mathrm{p}=0.04)$, pain location (leg vs. low back, $\mathrm{p}=0.05$ ) and scores of NPRS ( $\mathrm{p}=0.001)$, RMDQ, HADS and work status $(\mathrm{P}<0.0001)$.
\end{abstract}

Conclusions: Psychosocial and workplace risk factors are prevalent following a work-related low back injury. An increased number of flag signs is associated with an increased report of disability, pain, anxiety, depression and a less favorable work status.

Keywords: Flag signs; Risk factors; Workers Compensation; Lumbar spine

\section{Introduction}

Factors such as attitudes, negative beliefs, depressive mood state, anxiety disorder and certain social factors can interact with pain behaviour and are cumulatively referred to as psychosocial factors [1]. The value of psychosocial flags in predicting prolonged disability has been recognized for two decades [2-7]. The other significant factor that has established a link with prolonged disability is the work situation $[3,4,8]$. Job dissatisfaction and low control to make decisions about work have an adverse effect on health, significant enough to lead to hospitalization [8].

To match the color-coded theme with red flag signs that refer to serious physical pathology, psychological and work-related flag signs have also been given a specific color-coded reference. Yellow flags reflect psychosocial factors such as fears of pain or injury, preference for passive treatment, having negative pain beliefs and distressed affect [5]. Black flags refer to the nature of the work, insurance and compensation system under which workplace injuries are managed. Blue flags represent the workplace environmental risk factors such as a stressful, unsupportive and excessively demanding environment [4]. While black flags are caused by the actual workplace conditions, blue flags are the individual perceptions about work.

Occupational low back pain is associated with prolonged sick leave, loss of work continuity and productivity and over-utilization of the health care system [9-12]. There is evidence that psychosocial yellow flag signs [2-7] and workplace blue and black flag signs $[3,4]$ play important roles in persisting symptoms and disability. However, there is little information on the prevalence and 
significance of the specific flag signs in injured workers and there remains a gap in our understanding of how the psychosocial and workplace issues are linked together. Further examination of these factors is therefore warranted. The objectives of this study were to examine the prevalence of the yellow, blue and black flags in workers who had sustained an occupational lumbar injury and to explore the relationship between the presence and number of these signs with the level of pain, disability, anxiety, depression and ability to work.

\section{Materials and Methods}

This study involved a review of the electronic files of injured workers with an active claim related to the lumbar spine. All patients were seen at a specialty spine clinic funded by the Ontario Workplace Safety and Insurance Board (WSIB). All workers were examined by an orthopedic surgeon with fellowship training in spinal surgery and a specialized physical therapist. The recommendations for further investigations and treatment including appropriate accommodations for return to work were made by the assessing team. The referrals to the clinic were made by nurse consultants or case managers employed by the WSIB.

\section{Data collection}

The data related to demographics, work status, history of injury, clinical examination, presence and number of flag signs and surgical candidacy were extracted from a standardized PDF form completed by the clinicians.

The questions relevant to flag signs covered a variety of areas known to be related to barriers to recovery such as suboptimal coping, preference for passive treatment and family and workplace issues. Flag signs were marked as positive when the presence of a certain trait was established or when the patient answered positively to a question. If the worker's concern was not included in the assessment form, the physical therapist who interviewed the worker chose the category of "other". The yellow and black flag signs addressed nine questions each and the blue flags addressed three questions (Appendix A). The prevalence of flag signs within each color-coded category was calculated as the presence of at least one positive response. To examine the accumulative impact of all flag signs, patients were categorized into three groups: patients with no flag signs (Group1), $<3$ flag signs (Group2), and $\geq 3$ flag signs (Group3) [13]. The approval for using the existing data was obtained from the Research Ethics Board of the local institute.

\section{Outcome measures}

All patients completed a disability outcome measure, the Roland Morris Disability Questionnaire (RMDQ) [14], a Numeric Pain Rating Scale (NPRS) and the Hospital Anxiety and Depression Scale (HADS) [15] while waiting to be seen by the clinicians. The RMDQ is a validated [14,16-18] self-rated questionnaire that has 24 statements concerning the perceptions of back pain and associated disability (0-24). The items include 15 statements on physical ability and activity, three related to sleep and rest, two on psychosocial factors, two on household management, one related to eating and one regarding pain frequency. The NPRS ranges from 0 to 10 with 0 being no pain and 10 being the worst pain. The NPRS has established validity for clinical use [19,20]. The HADS is a 14 item scale [15] with seven items relating to anxiety and seven items relating to depression ranging from 0 to 21 for anxiety and 0 to 21 for depression. The HADS scores of $<7$ are considered within the normal range for either subcategory, while scores between 8 and 10 indicate presence of the respective state. Scores of 11 or higher indicate probable presence of a mood disorder [15]. The HADS has acceptable measurement properties for patients with musculoskeletal conditions [21].

\section{Statistical analysis}

The sample size was calculated based on the expected prevalence of flag signs, using the formula: $n=\frac{Z^{2} P(1-P)}{d^{2}}$,

where $Z$ for a level of confidence of $95 \% \mathrm{CI}$ is 1.96, $P$ is the expected prevalence, and $d$ is precision[22]. Grimmer-Somers has noted a prevalence of $13 \%$ for yellow flags in patients with low back pain [7]. With the $Z$ statistic of $1.96, P$ of 0.13 , and $d$ of $5 \%$ (width of $\mathrm{CI}=2 d$ ), a minimum of 174 injured workers was required.

Descriptive statistics were performed and an estimate of prevalence of each flag category was calculated as the number of patients with at least one positive flag sign/total number of workers. As noted, patients were categorized into three groups: no flag signs (Group1), <3 flag signs (Group2), and $\geq 3$ flag signs (Group3). Logistic regressions examined the association between the group variables and patient characteristics. Statistical analysis was performed using SAS ${ }^{\circledast}$ version 9.1.3 (SAS ${ }^{\varpi}$ Institute, Cary, NC). Statistical results are reported using 2 -tailed $\mathrm{p}$ values with significance set at $\mathrm{p}<0.05$.

\section{Results}

The data of 250 consecutive patients, 74 (30\%) females, $176(70 \%)$ males, (mean age=45, SD=11, range 23 to 73 years) were reviewed. The average time between the most recent injury and date of assessment was $8(\mathrm{SD}=13)$ months. The majority of patients $(209,84 \%)$ had a diagnosis of lumbar strain with 19 (8\%) disc herniation and 22 (9\%) fractures. Two hundred and seventeen (87\%) patients had a back dominant pain and 33(13\%) had a leg dominant pain.

Prevalence of yellow flag signs was 69\% (173/250). The black flag signs which represented the actual work-place difficulties had a prevalence of $65 \%(162 / 250)$. The blue signs were the least prevalent being $18 \%(46 / 250)$. A shorter list of blue flag questions is 
expected to have contributed to a lower prevalence of blue flags. Figures 1-3 show the relative frequency of positive responses to each question representing yellow, black and blue flag sign categories.

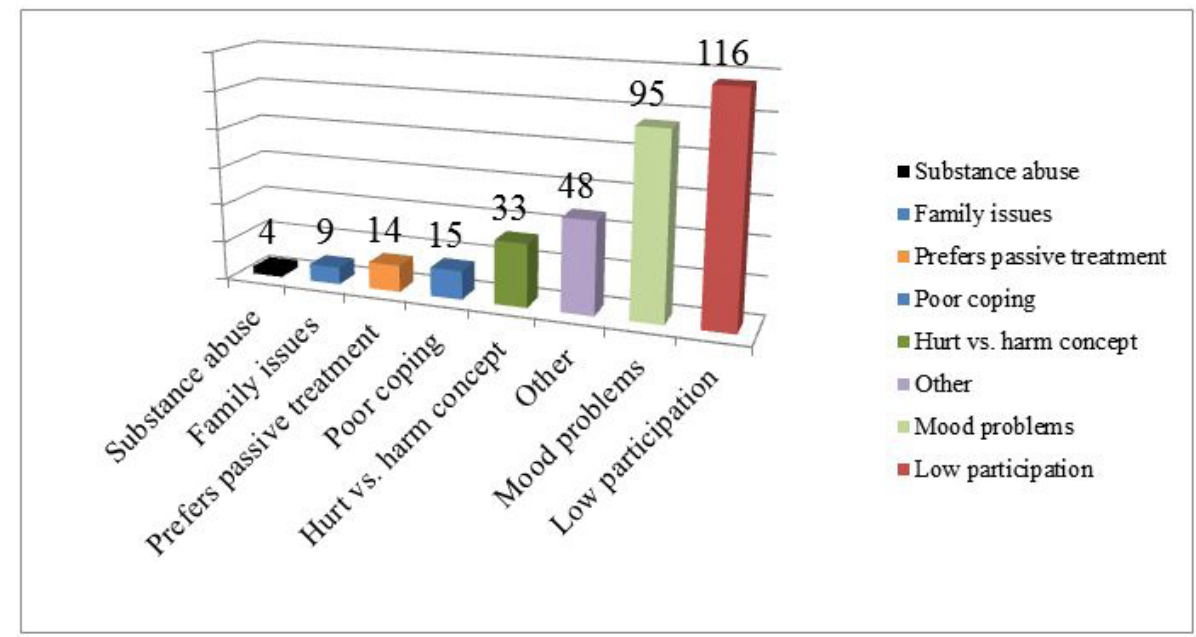

Some question responses overlapped

Figure 1: Frequency of yellow flag question responses $(\mathrm{N}=173)$

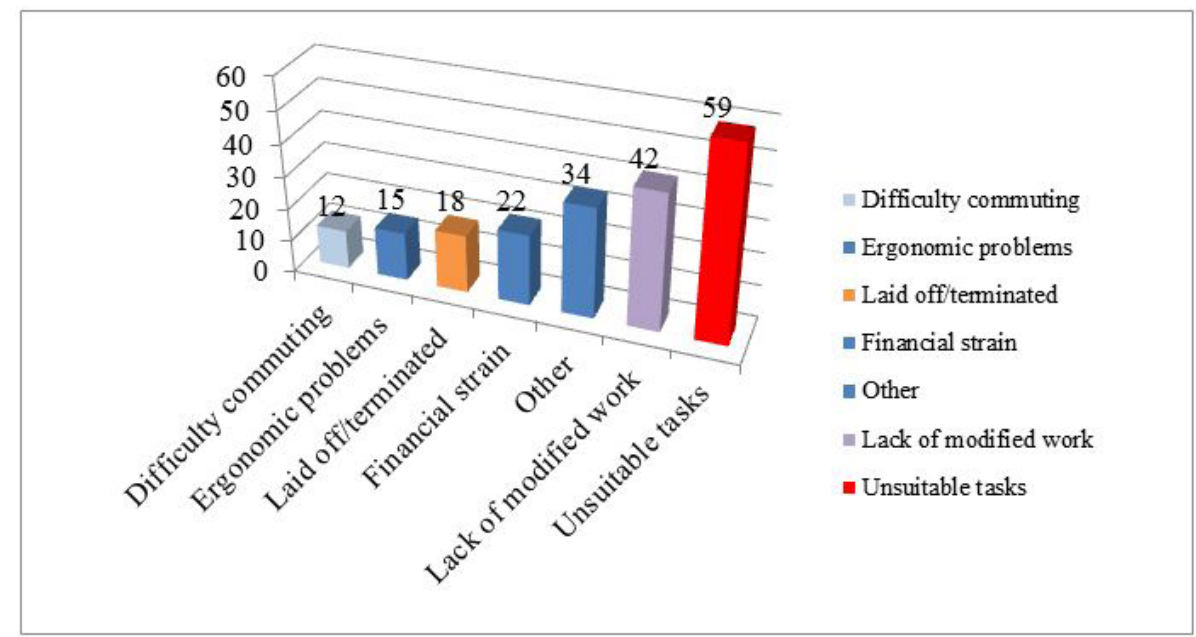

Some question responses overlapped

Figure 2: Frequency of black flag question responses $(\mathrm{N}=162)$

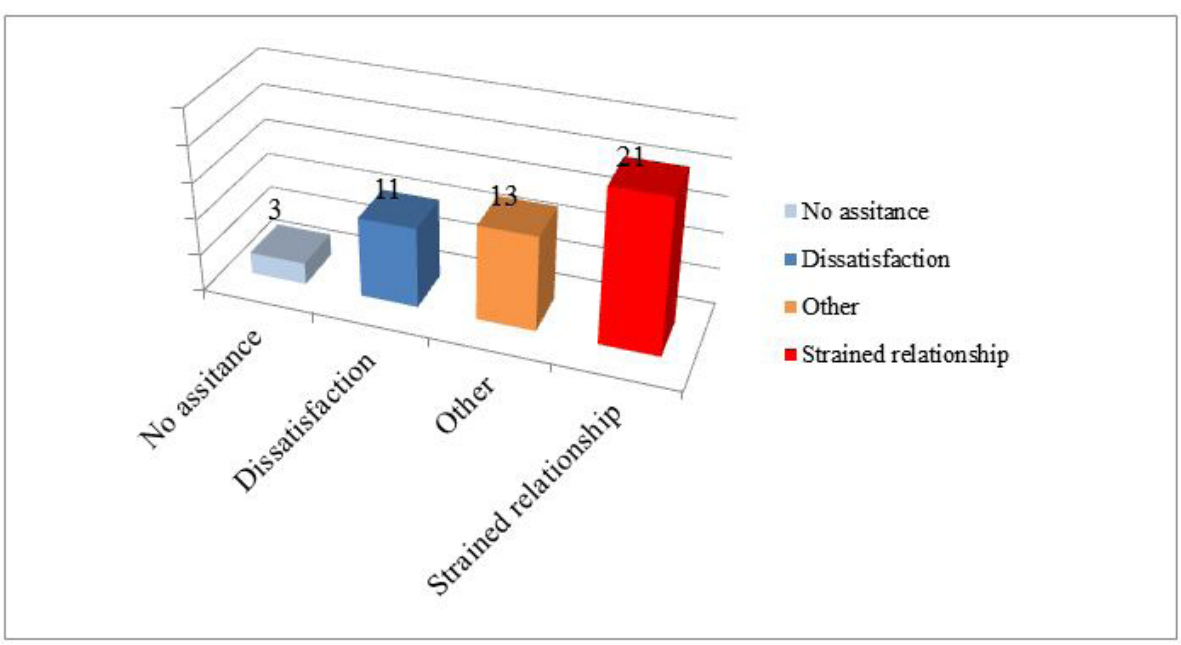

Some question responses overlapped

Figure 3: Frequency of Blue Flag question responses $(\mathrm{N}=46)$

Thirty-nine (16\%) patients had no flag signs (Group1). Out of remaining patients, 109 (43\%) had one or two flag signs (Group2) and $102(41 \%)$ had three or more flag signs (Group3). Table 1 shows the distribution of group characteristics. Age, sex, mechanism of injury (traumatic vs. insidious), employment duration, job demands or type of diagnosis were not associated with the number of signs at a statistically significant level $(\mathrm{p}>0.05)$. 


\begin{tabular}{|c|c|c|c|c|c|}
\hline $\begin{array}{c}\text { Variables } \\
\text { Mean (SD) } \\
\text { Number (\%) }\end{array}$ & $\begin{array}{l}\text { Group1 } \\
(\mathrm{N}=39)\end{array}$ & $\begin{array}{l}\text { Group2 } \\
(\mathrm{N}=109)\end{array}$ & $\begin{array}{l}\text { Group3 } \\
(\mathrm{N}=102)\end{array}$ & $\begin{array}{l}\text { Wald Chi square } \\
\text { P values }\end{array}$ & Odds Ratios* \\
\hline Age & $44(13)$ & $45(10)$ & $45(10)$ & $\mathrm{W}=0.89, \mathrm{p}=0.77$ & \\
\hline $\begin{array}{l}\text { Sex } \\
\text { Female } \\
\text { Male }\end{array}$ & $\begin{array}{l}13(33 \%) \\
26(67 \%)\end{array}$ & $\begin{array}{l}26(24 \%) \\
83(76 \%)\end{array}$ & $\begin{array}{l}35(34 \%) \\
67(66 \%)\end{array}$ & $\mathrm{W}=0.74, \mathrm{p}=0.39$ & \\
\hline $\begin{array}{l}\text { Symptom duration } \\
\text { (months) }\end{array}$ & $5.8(6)$ & $6.1(8)$ & $9.3(16)$ & $\mathrm{W}=4.19, \mathrm{p}=0.04$ & $\mathrm{OR}=0.98(0.96-0.99)$ \\
\hline $\begin{array}{l}\text { Employment duration } \\
\text { (months) }\end{array}$ & $97(89)$ & 104(109) & $76(85)$ & $\mathrm{W}=2.47, \mathrm{p}=0.12$ & \\
\hline $\begin{array}{l}\text { Job Demands } \\
\text { Light/sedentary } \\
\text { Moderate } \\
\text { Heavy }\end{array}$ & $\begin{array}{r}6(15 \%) \\
22(56 \%) \\
11(28 \%)\end{array}$ & $\begin{array}{c}10(9 \%) \\
59(55 \%) \\
39(36 \%)\end{array}$ & $\begin{array}{c}6(6 \%) \\
62(61 \%) \\
34(33 \%)\end{array}$ & $\mathrm{W}=3.05, \mathrm{p}=0.22$ & \\
\hline Traumatic injury & $28(72 \%)$ & $91(83 \%)$ & $84(82 \%)$ & $\mathrm{W}=1.01, \mathrm{p}=0.31$ & $\underline{-}$ \\
\hline $\begin{array}{l}\text { Pain site } \\
\text { Back dominant } \\
\text { Leg dominant }\end{array}$ & $\begin{array}{r}30(79 \%) \\
8(21 \%)\end{array}$ & $\begin{array}{l}94(86 \%) \\
15(14 \%)\end{array}$ & $\begin{array}{c}93(91 \%) \\
9(9 \%)\end{array}$ & $\mathrm{W}=3.06, \mathrm{p}=0.05$ & $\mathrm{OR}=0.50(0.25-1.01)$ \\
\hline $\begin{array}{l}\text { Type of diagnosis } \\
\text { Lumbar strain } \\
\text { Fracture } \\
\text { Disc herniation }\end{array}$ & $\begin{array}{c}36(92 \%) \\
2(5 \%) \\
1(3 \%)\end{array}$ & $\begin{array}{c}86(79 \%) \\
13(12 \%) \\
10(9 \%)\end{array}$ & $\begin{array}{c}87(85 \%) \\
7(7 \%) \\
8(8 \%)\end{array}$ & $\mathrm{W}=0.39, \mathrm{p}=0.82$ & \\
\hline $\begin{array}{l}\text { Subjective outcomes } \\
\text { NPRS }(0-10) \\
\text { RMDQ }(0-24) \\
\text { HADS Anxiety }(0-21) \\
\text { HADS Depression }(0-21)\end{array}$ & $\begin{array}{r}3.6(3) \\
10(6) \\
6(4) \\
5(4)\end{array}$ & $\begin{array}{r}3.8(3) \\
13(7) \\
8(5) \\
7(5)\end{array}$ & $\begin{array}{r}5.2(3) \\
17(7) \\
12(5) \\
11(5)\end{array}$ & $\begin{array}{l}\mathrm{W}=11.10, \mathrm{p}=0.001 \\
\mathrm{~W}=30.10, \mathrm{p}<0.0001 \\
\mathrm{~W}=32.81, \mathrm{p}<0.0001 \\
\mathrm{~W}=46.21, \mathrm{P}<0.0001\end{array}$ & $\begin{array}{l}\mathrm{OR}=0.87(0.81-0.95) \\
\mathrm{OR}=0.90(0.87-0.94) \\
\mathrm{OR}=0.86(0.83-0.91) \\
\mathrm{OR}=0.84(0.80-0.88)\end{array}$ \\
\hline $\begin{array}{l}\text { Anxiety } \\
\text { Normal }(\leq 7) \\
\text { Borderline abnormal }(7-10) \\
\text { Abnormal }(>11) \\
\text { Depression } \\
\text { Normal }(\leq 7) \text {. } \\
\text { Borderline abnormal }(7-10) \\
\text { Abnormal }(>11)\end{array}$ & $\begin{array}{c}23(59 \%) \\
9(23 \%) \\
7(18 \%) \\
\\
31(79 \%) \\
2(5 \%) \\
6(15 \%)\end{array}$ & $\begin{array}{l}53(47 \%) \\
17(16 \%) \\
39(36 \%) \\
60(55 \%) \\
22(20 \%) \\
27(25 \%)\end{array}$ & $\begin{array}{l}21(21 \%) \\
18(17 \%) \\
63(63 \%) \\
24(24 \%) \\
16(16 \%) \\
62(65 \%)\end{array}$ & $\mathrm{W}=29.71, \mathrm{p}<0.0001$ & $\begin{array}{l}\mathrm{OR}=4.61(2.66-8.33) \\
\mathrm{OR}=2.54(1.28-5.03)\end{array}$ \\
\hline $\begin{array}{l}\text { Work status } \\
\text { Not-working } \\
\text { Working part time } \\
\text { Working full time }\end{array}$ & $\begin{array}{r}9(23 \%) \\
9(23 \%) \\
21(54 \%)\end{array}$ & $\begin{array}{l}45(42 \%) \\
22(20 \%) \\
42(39 \%)\end{array}$ & $\begin{array}{l}73(71 \%) \\
10(10 \%) \\
19(19 \%)\end{array}$ & $31.96, \mathrm{p}<0.0001$ & $\begin{array}{ll}\mathrm{OR}=4.49 & (2.57-7.87) \\
\mathrm{OR}=3.92 & (1.97-7.84)\end{array}$ \\
\hline
\end{tabular}

Group 1: No flag signs

Group 2: Less than three flag signs

Group 3: Three or more flag signs

HADS: Hospital Anxiety and Depression Scale

NPRS: Numeric pain rating score

OR: Odds ratios (provided for significant Wald statistics)

RMDQ: Roland Morris Disability Questionnaire

SD: Standard deviation

ORs for work status are provided for full time vs. not working, and part time vs. not working.

ORs for anxiety and depression are provided for normal vs. abnormal and borderline abnormal vs. abnormal.

Table 1: Characteristics of patients with and without flag signs $(\mathrm{N}=250)$

Group 3 suffered from more chronic symptoms $(\mathrm{p}=0.04)$. Leg dominant pain was more prevalent in Group $1(\mathrm{p}=0.05)$. There was a statistically significant difference $(\mathrm{p}<0.0001)$ in work status among groups with the Groupl having the most favorable status (Table 1). In addition, there was a statistically significant relationship between the presence and number of flag signs (as indicated in group assignment) and the scores of RMDQ, NPRS and HADS with the higher levels of disability, pain, anxiety and depression reported by patients with higher number of flag signs (Table1, Figure 4). In terms of specific HADS subcategories, Group 1 included the majority of workers with normal anxiety (59\%) and normal depression HADS scores (79\%). Group 3 included most of the patients with high scores of anxiety (63\%) and depression (65\%) reflecting a significant affect/mood in patients with 3 or more flag signs. 


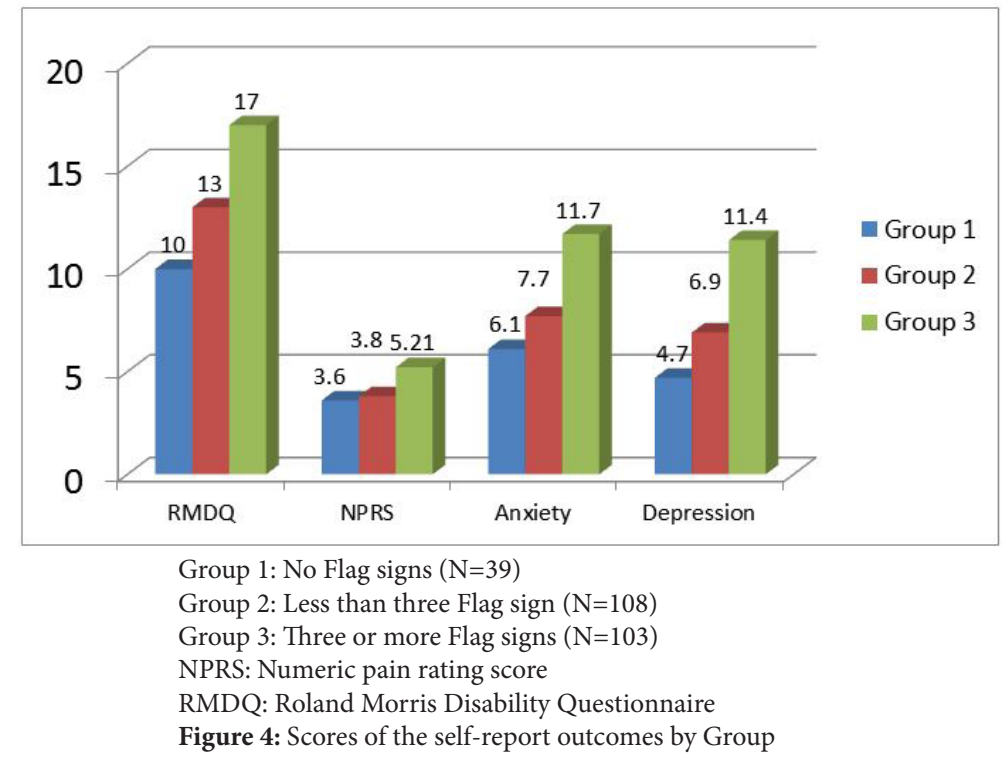

\section{Discussion}

In the present study, the prevalence of yellow, black and blue flag signs was $69 \%, 65 \%$ and $18 \%$ respectively. We observed a positive linear relationship between cumulative number of flag signs and a higher report of disability, pain, depression, anxiety and work status.

There is a large body of literature on generic risk factors for prolonged lower back disability. However, due to the wide variation in methodology, outcome measures and populations used in the original studies and potential mediators and confounding factors, the results of systematic reviews remain somewhat inconclusive. Verkerk et al. [23] reported conflicting evidence for the association between a favorable outcome and age, sex, pain intensity and physical job demands. Kent and Keating [24] concluded that there was little certainty regarding the most important prognostic factors. Hayden et al. [25] acknowledged the significance of methodological shortcomings in the primary and review literature and the uncertainty about the reliability of conclusions regarding prognostic factors for low back pain.

Despite difficulty in identifying generic risk factors (sex, age, etc.) that contribute to a poor recovery of back pain, the role of psychosocial factors in predicting chronic low back pain is well established [26-35]. In addition, the impact of workplace factors on disability has been well documented [3,6,36-39].

In the only study that has specifically examined the prevalence of yellow flags as defined by Kendall et al. [5], Grimmer-Sommers and colleagues [7] administrated a psychosocial screening instrument referred to as the Yellow Flags Screening Instrument (YFSI), an earlier version of Örebro Musculoskeletal Pain Questionnaire [40]. In this study, of 328 claimants who provided yellow flag scores on the second visit to a general medical practitioner, 67(20\%) had scores less than 49 (deemed to be low risk of developing chronic LBP), $242(73 \%)$ had a score of $<90$, expected to exhibit recovery within the expected time period, and $13 \%$ had a high score for development of chronic pain behaviour. Considering $73 \%$ had no or minimal risk of developing persistent pain behaviors, the authors felt that use of YSFI should be revisited by the family physicians as most patients did not comply with the score categories originally recommended.

The lower prevalence of yellow flag signs reported by Grimmer-Somers et al. [7] is related to a different outcome measure used in their study, a subjective questionnaire vs. the clinician's interview used in this study and difference in patients' demographics such as younger age ( 39 vs. 45 years) and shorter symptom duration (12 to 71 days vs. 6 to 9 months). In addition, the type of injury in their study involved road accidents and work or community injuries, where our sample included more homogenous occupational injuries. Finally, types of clinics were different between studies being general medical clinics in the Grimmer-Somers's study vs. a tertiary care clinic in our study. Tertiary specialized care centres usually accommodate patients with more serious conditions and those with failed conservative treatment who may be more susceptible to chronic pain behaviour.

\section{Implications for management}

It has been noted that certain aspects of yellow flags such as negative beliefs or perceptions are amenable to change [2] and should be the target of management of low back pain. In a study by Shaw et al. 23 potentially modifiable risk factors describing workplace and personal domains were identified through a literature review [41]. The workplace interventions, graded activity exposure, cognitive restructuring of pain beliefs, return to work coordination, improving emotional distress and job dissatisfaction were all noted as modifiable factors by Shaw et al. [41]. 
The majority of our patients had a diagnosis of lumbar strain with a good prognosis for full recovery. The clinicians who are involved in the assessment or care of injured workers with the diagnosis of lumbar strain or uncomplicated mechanical low back pain have an important role in the management of these individuals. Evidence of flag signs should prompt the clinician to potential vulnerability of the patient to an increased perception of pain, physical dysfunction and the emotional distress. The impact of the risk factors can be reduced by explaining the benefits of active treatment, providing input on the benign nature of the pathology, by changing perceptions about pain and highlighting the difference between hurt versus harm. The appropriate involvement of the family members is a key to recovery of injured workers which can be achieved by discouraging the overprotective behaviour of the family while maintaining a healthy interest and support. The importance of communication between the clinicians and stakeholders and ongoing support by supervisors at the workplace should not be ignored $[2,33,42]$.

In summary, in light of the costly nature of low back pain [9-12,43], the poor correlation between ongoing symptoms and anatomic, clinical and imaging findings and a strong link with personal, psychological and workplace factors, screening psychological risk factors either in the form of an interview or a questionnaire is expected to assist with a more effective and specific intervention. This could lead to the modification of unhealthy behaviors and incorporating workplace interventions in a timely fashion which may reduce the chance of chronic or permanent disability.

\section{Conclusions}

Psychosocial and workplace risk factors are prevalent following a work-related low back injury. An increased number of flag signs is associated with an increased report of disability, pain, anxiety, depression and a less favorable work status.

\section{Appendix}

\section{References}

1. Innes SI (2005) Psychosocial factors and their role in chronic pain: A brief review of development and current status. Chiropr Osteopat 13: 6.

2. Nicholas MK, Linton SJ, Watson PJ, Main CJ; Decade of the Flags (2011) Working Group: Early identification and management of psychological risk factors ("yellow flags") in patients with low back pain: a reappraisal. Phys Ther 91: 737-53.

3. Shaw WS, van der Windt DA, Main CJ, Loisel P, Linton SJ, Decade of the Flags (2009) Working Group: Early patient screening and intervention to address individual-level occupational factors ("blue flags") in back disability. J Occup Rehabil 19: 64-80.

4. Main C, Burton A (2000) Economic and occupational influences on pain and disability. In: Main CJ, Spanswick CC, eds. Pain Management: An Interdisciplinary Approach. In Edited by Anonymous Churchill Livingstone: Churchill Livingstone 63-87.

5. Kendall N, Linton S, Main C (1997) Guide to Assessing Psychosocial Yellow Flags in Acute Low Back Pain: Risk Factors for Long-Term Disability and Work Loss. Wellington, New Zealand: Accident Rehabilitation and Compensation Insurance Corporation of New Zealand and the National Health Committee.

6. Rapala K, Walczak P, Truszczynska A, Lukawski S, Nowak-Misiak M (2012) Diagnostic and therapeutic problems of back pain syndromes and their distribution according to a colour coding system of flags. Ortop Traumatol Rehabil 14: 215-27.

7. Grimmer-Somers K, Prior M, Robertson J (2008) Yellow flag scores in a compensable New Zealand cohort suffering acute low back pain. J Pain Res 1: 15-25.

8. Kaila-Kangas L, Kivimaki M, Riihimaki H, Luukkonen R, Kirjonen J, et al. (2004) Psychosocial factors at work as predictors of hospitalization for back disorders: a 28-year follow-up of industrial employees. Spine 29: 1823-30.

9. Global Burden of Disease Study 2013 Collaborators (2013) Global, regional, and national incidence, prevalence, and years lived with disability for 301 acute and chronic diseases and injuries in 188 countries, 1990-2013: a systematic analysis for the Global Burden of Disease Study 2013. Lancet 386: 743-800.

10. Lim KL, Jacobs P, Klarenbach S (2006) A population-based analysis of healthcare utilization of persons with back disorders: results from the Canadian Community Health Survey 2000-2001. Spine (Phila Pa 1976) 31: 212-8.

11. Katz JN (2006) Lumbar disc disorders and low-back pain: socioeconomic factors and consequences. J Bone Joint Surg Am 88 Suppl 2:21-24.

12. Gandjour A, Telzerow A, Lauterbach KW, INTERCARE International Investigators (2005) European comparison of costs and quality in the treatment of acute back pain. Spine (Phila Pa 1976) 30: 969-75.

13. Waddell G, Pilowsky I, Bond MR (1989) Clinical assessment and interpretation of abnormal illness behaviour in low back pain. Pain 39 41-53.

14. Roland M, Morris R (1983) A study of the natural history of back pain. Part I: development of a reliable and sensitive measure of disability in low-back pain. Spine (Phila Pa 1976) 8: 141-4.

15. Zigmond AS, Snaith RP (1983) The hospital anxiety and depression scale. Acta Psychiatr Scand 67: 361-70.

16. Chiarotto A, Maxwell LJ, Terwee CB, Wells GA, Tugwell P, et al. (2016) Roland-Morris Disability Questionnaire and Oswestry Disability Index: Which Has Better Measurement Properties for Measuring Physical Functioning in Nonspecific Low Back Pain? Systematic Review and Meta-Analysis. Phys Ther 96: 1620-37. 17. Turner JA, Fulton-Kehoe D, Franklin G, Wickizer TM, Wu R (2003) Comparison of the Roland-Morris Disability Questionnaire and generic health status measures: a population-based study of workers' compensation back injury claimants. Spine (Phila Pa 1976) 28: 1061-7.

18. Spanjer J, Groothoff JW, Brouwer S (2011) Instruments used to assess functional limitations in workers applying for disability benefit: a systematic review. Disabil Rehabil 33(23-24): 2143-150.

19. Ferreira-Valente MA, Pais-Ribeiro JL, Jensen MP (2011) Validity of four pain intensity rating scales. Pain 152: 2399-404.

20. Williamson A, Hoggart B (2005) Pain: a review of three commonly used pain rating scales. J Clin Nurs 14: 798-804.

21. Pallant JF, Tennant A (2007) An introduction to the Rasch measurement model: an example using the Hospital Anxiety and Depression Scale (HADS). Br J Clin Psychol 46: 1-18.

22. Daniel W (1999) Biostatistics: A foundation for analysis in the health Sciences: 7th edition ed. New York: John Wiley and Sons.

23. Verkerk K, Luijsterburg PA, Miedema HS, Pool-Goudzwaard A, Koes BW (2012) Prognostic factors for recovery in chronic nonspecific low back pain: a systematic review. Phys Ther 92: 1093-108. 
24. Kent PM, Keating JL (2008) Can we predict poor recovery from recent-onset nonspecific low back pain? A systematic review. Man Ther 13: 12-28. 25. Hayden JA, Chou R, Hogg-Johnson S, Bombardier C (2009) Systematic reviews of low back pain prognosis had variable methods and results: guidance for future prognosis reviews. J Clin Epidemiol 62: 781-796.e1.

26. Pincus T, Burton AK, Vogel S, Field AP (2002) A systematic review of psychological factors as predictors of chronicity/disability in prospective cohorts of low back pain. Spine (Phila Pa 1976) 27: E109-20.

27. Gatchel RJ, Polatin PB, Mayer TG (1995) The dominant role of psychosocial risk factors in the development of chronic low back pain disability. Spine (Phila Pa 1976) 20: 2702-9.

28. Shaw WS, Hartvigsen J, Woiszwillo MJ, Linton SJ, Reme SE (2016) Psychological Distress in Acute Low Back Pain: A Review of Measurement Scales and Levels of Distress Reported in the First 2 Months After Pain Onset. Arch Phys Med Rehabil 97: 1573-87.

29. Fishbain DA, Cole B, Cutler RB, Lewis J, Rosomoff HL, et al. (2003) A structured evidence-based review on the meaning of nonorganic physical signs: Waddell signs. Pain Med 4: 141-81.

30. Fishbain DA, Cutler RB, Rosomoff HL, Rosomoff RS (2004) Is there a relationship between nonorganic physical findings (Waddell signs) and secondary gain/ malingering? Clin J Pain 20: 399-408.

31. Main CJ, Waddell G (1998) Behavioral responses to examination. A reappraisal of the interpretation of "nonorganic signs". Spine (Phila Pa 1976) 23: 2367-71.

32. Bletzer J, Gantz S, Voigt T, Neubauer E, Schiltenwolf M (2016) Chronic low back pain and psychological comorbidity: A review. Schmerz 31: 93-101.

33. Blyth FM, Macfarlane GJ, Nicholas MK (2007) The contribution of psychosocial factors to the development of chronic pain: the key to better outcomes for patients? Pain 129: 8-11.

34. Bongers PM, Kremer AM, ter Laak J (2002) Are psychosocial factors, risk factors for symptoms and signs of the shoulder, elbow, or hand/wrist?: A review of the epidemiological literature. Am J Ind Med 2002, 41: 315-42.

35. Compare A, Marchettini P, Zarbo C (2016) Risk Factors Linked to Psychological Distress, Productivity Losses, and Sick Leave in Low-Back-Pain Employees: A Three-Year Longitudinal Cohort Study. Pain Res Treat 2016: 3797493.

36. Shaw WS, Pransky G, Fitzgerald TE (2001) Early prognosis for low back disability: intervention strategies for health care providers. Disabil Rehabil 23: 815-28.

37. Crook J, Milner R, Schultz IZ, Stringer B (2002) Determinants of occupational disability following a low back injury: a critical review of the literature. J Occup Rehabil 12: 277-95.

38. Steenstra IA, Verbeek JH, Heymans MW, Bongers PM (2005) Prognostic factors for duration of sick leave in patients sick listed with acute low back pain: a systematic review of the literature. Occup Environ Med 62: 851-60.

39. Hartvigsen J, Lings S, Leboeuf-Yde C, Bakketeig L (2004) Psychosocial factors at work in relation to low back pain and consequences of low back pain; a systematic, critical review of prospective cohort studies. Occup Environ Med 61: e2.

40. Linton SJ, Boersma K (2003) Early identification of patients at risk of developing a persistent back problem: the predictive validity of the Orebro Musculoskeletal Pain Questionnaire. Clin J Pain 19: 80-6.

41. Shaw WS, Linton SJ, Pransky G (2006) Reducing sickness absence from work due to low back pain: how well do intervention strategies match modifiable risk factors? J Occup Rehabil 16: 591-605.

42. Franche RL, Cullen K, Clarke J, Irvin E, Sinclair S, Institute for Work \& Health (IWH) Workplace-Based RTW Intervention Literature Review Research Team (2005) Workplace-based return-to-work interventions: a systematic review of the quantitative literature. J Occup Rehabil 15: 607-31.

43. Wasiak R, Kim J, Pransky G (2006) Work disability and costs caused by recurrence of low back pain: longer and more costly than in first episodes. Spine (Phila Pa 1976) 31: 219-25. 